\title{
Outer membrane protein and biotype analysis of non-serotypable strains of Haemophilus influenzae
}

\author{
CHRISTINE H COVERDALE, G S TEMPLE \\ From the Department of Microbiology, Hull Royal Infirmary
}

SUMMARY Strains of Haemophilus influenzae $(n=161)$ were isolated from inpatients with symptoms of pulmonary infection. Conventional tests showed that 144 strains were non-serotypable and all belonged to one of eight biotypes. The common biotypes were $2(41 \%), 3(27 \cdot 1 \%), 1(13 \cdot 2 \%)$ and $5(10.4 \%)$. The outer membrane protein (OMP) profiles of 59 non-serotypable strains were examined by sodium dodecyl sulphate-polyacrylamide gel electrophoresis (SDS-PAGE). A comparison of OMP profiles suggested a possible association between several strains belonging to biotype 2 . Although no clear correlation was established between biotype or OMP profile cluster groups and the age or clinical state of the patients from whom the strains were isolated, SDS-PAGE analysis was a useful technique for the epidemiological study of non-serotypable $H$ influenzae.

Non-serotypable (non-encapsulated) strains of Haemophilus influenzae are now regarded as a major cause of respiratory infection in adults and have been implicated in other infections which include urogenital disease, meningitis, bacteraemia and otitis media in children.' A scheme for the differentiation of $H$ influenzae into a number of biotypes was described by Kilian. ${ }^{2}$ This biotyping scheme has been used in several studies ${ }^{3-7}$ in an attempt to understand the epidemiology of diseases caused by non-serotypable strains. It lacked sensitivity to strain variation, however, as only six biotypes were recognised. ${ }^{8}$ Recently the biotyping scheme has been extended to include an additional two biotypes. ${ }^{910}$

A subtyping scheme, based on sodium dodecyl sulphate-polyacrylamide gel electrophoresis (SDSPAGE) of outer membrane protein (OMP) profiles has been used to further differentiate non-serotypable strains of $H$ influenzae." Although non-serotypable strains have exhibited considerable variation in the number and relative molecular mass $\left(\mathbf{M}_{\mathrm{r}}\right)$ of their OMPs, it has been suggested that non-serotypable strains from the same anatomical site may be related. ${ }^{12}$ A possible association between biotype and subtype remains unclear.

\section{Material and methods}

Over five months 161 strains of $H$ influenzae were isolated from sputum specimens of inpatients with Accepted for publication 1 December 1988 pulmonary infection on $10 \%$ chocolatised horse blood agar (with $5 \mu \mathrm{g} / \mathrm{ml}$ cloxacillin) incubated at $37^{\circ} \mathrm{C}$ in $7.5 \%$ carbon dioxide for 18 hours.

The identity of each isolate was determined by its colonial morphology and growth requirement for nicotinamide adenine dinucleotide (NAD) and haemin (Sigma Chemicals Ltd).

Isolates were serotyped by slide agglutination with antiserum against capsular antigen types $a$ to $f$ (Wellcome Diagnostics Ltd). Non-serotypable strains were assigned to one of eight biotypes on the basis of indole production, urea hydrolysis, and ornithine decarboxylation. ${ }^{2910}$

Fifty nine non-serotypable strains of $H$ influenzae were subjected to OMP subtyping. They included 15 strains each of biotypes 1,2 , and 5, and 14 strains of biotype 3 . The strains representative of biotypes 1,2 , and 3 were chosen at random. Outer membranes were prepared by a modification of the rapid microprocedure of Carlone et al ${ }^{13}$ for the isolation of detergent-insoluble OMPs. Briefly, bacterial strains were cultured in $20 \mathrm{ml}$ of brain heart infusion broth (Oxoid Ltd, supplemented with $10 \mu \mathrm{g}$ each of NAD and haemin) and incubated at $37^{\circ} \mathrm{C}$ for 18 hours on an orbital shaker (100 rpm). The optical density of the culture $(600 \mathrm{~nm})$ was adjusted to between 0.5 and 0.6 with sterile broth. The cells were harvested by centrifugation at $6000 \times g$ for 10 minutes at $4^{\circ} \mathrm{C}$. The pellet was washed once in cold $\left(4^{\circ} \mathrm{C}\right) 10 \mathrm{mM}$ HEPES ( $N$-2-hydroxyethylpiperazine- $N^{n}$-2-ethanesulfonic acid, Sigma Chemicals Ltd) buffer (pH 7.4) 
Table 1 Biotypes isolated from different age groups

\begin{tabular}{|c|c|c|c|c|c|c|c|c|c|c|}
\hline \multirow[b]{3}{*}{ Age (years) } & \multirow{3}{*}{$\begin{array}{l}\text { No of } \\
\text { patients }\end{array}$} & \multicolumn{8}{|c|}{ No of strains isolated } & \multirow[b]{3}{*}{ Total } \\
\hline & & \multicolumn{8}{|c|}{ Biotype } & \\
\hline & & 1 & 2 & 3 & 4 & 5 & 6 & 7 & 8 & \\
\hline $\begin{array}{l}0-9 \\
10-19 \\
20-29 \\
30-39 \\
40-49 \\
50-59 \\
60-69 \\
70-79 \\
80-89 \\
90-99 \\
\text { Unknown }\end{array}$ & $\begin{array}{r}4 \\
3 \\
2 \\
11 \\
12 \\
12 \\
35 \\
31 \\
17 \\
2 \\
5\end{array}$ & $\begin{array}{l}3 \\
5 \\
8^{*} \\
3++\end{array}$ & $\begin{array}{c}7 \\
6^{*} \\
7^{*} \\
16 \\
10 \\
9^{*}++ \\
1 \\
3\end{array}$ & $\begin{array}{l}1 \\
2 \\
2 \\
4 \\
4 \\
1 \\
9 \\
8 \\
5^{*} \\
1 \\
2\end{array}$ & 1 & $\begin{array}{l}2 \\
2 \\
2 \\
4 \ddagger \\
2\end{array}$ & $\begin{array}{l}1+ \\
2+\end{array}$ & 1 & $\begin{array}{l}3+ \\
2+\end{array}$ & $\begin{array}{r}4 \\
3 \\
2 \\
11 \\
13 \\
13 \\
36 \\
35 \\
20 \\
2 \\
5\end{array}$ \\
\hline
\end{tabular}

* The same biotype strain isolated from one patient on two separate occasions; tstrains of biotype 6 and biotype 8 were isolated from consecutive samples from one patient; $\ddagger$ the same biotype strain was isolated from one patient on three successive occasions; ++ strains of biotype 1 and biotype 2 were isolated from consecutive samples from one patient.

and, while kept on ice, sonicated (eight bursts, 10 seconds each burst at $40 \mathrm{~W}$, with 30 seconds between each burst). The cell membranes were sedimented at $15000 \times g$ for 30 minutes at $4^{\circ} \mathrm{C}$. Cytoplasmic membranes were solubilised with $2 \%$ sodium $N$-lauroylsarcosine (Sigma Chemicals Ltd) for 30 minutes at $23^{\circ} \mathrm{C}$, and centrifuged at $15000 \times g$ for two minutes to remove cellular debris. The membrane pellets were centrifuged at $15000 \times g$ for 30 minutes, washed once, and resuspended in $50 \mu \mathrm{l}$ of $10 \mathrm{mM}$ HEPES buffer.

Extracts of OMPs were prepared by boiling the membrane suspension with an equal volume of solubilising buffer ${ }^{14}$ for 10 minutes. Aliquots of the mixture were examined by PAGE. Electrophoresis was performed in the presence of SDS using the discontinuous buffer system of Laemmli ${ }^{15}$ with $15 \%$ $(\mathrm{w} / \mathrm{v})$ polyacrylamide as the resolving gel. Low molecular weight standards (Pharmacia Ltd) were included with each run. Gels were run at a constant current of $8 \mathrm{~mA}$ until the blue marker reached the bottom of the plate. The proteins were stained by immersion in $0.25 \%(\mathrm{w} / \mathrm{v})$ Coomassie brilliant blue $\mathrm{G}$ (Sigma Chemicals Ltd) in a mixture of glacial acetic $\mathrm{acid} / \mathrm{methanol} / \mathrm{distilled}$ water $(10: 45: 45, \mathrm{v} / \mathrm{v})$ for 30 minutes. The gels were destained in the above solvents in the ratio $7 \cdot 5: 5: 87 \cdot 5(\mathrm{v} / \mathrm{v})$, respectively.

Protein profile comparisons were made using the Dice coefficient of similarity. ${ }^{16}$ The diversity index was determined by the method of Shannon and Weaver. ${ }^{17}$

\section{Results}

Most $(144,89.4 \%)$ of the strains were non-serotypable. All strains were biotypable and eight distinct biotypes were represented.

Of the non-serotypable strains, $(91,63.2 \%)$ were isolated from patients between 60 and 89 years of age. The number of biotypes of $H$ influenzae isolated from patients of each age group is shown in table 1. For all

Table 2 Biotypes associated with pulmonary infection

\begin{tabular}{|c|c|c|c|c|c|c|c|c|c|c|}
\hline \multirow[b]{3}{*}{ Clinical diagnosis } & \multirow{3}{*}{$\begin{array}{l}\text { No of } \\
\text { patients }\end{array}$} & \multicolumn{8}{|c|}{ No of strains isolated } & \multirow[b]{3}{*}{ Total } \\
\hline & & \multicolumn{8}{|c|}{ Biotype } & \\
\hline & & 1 & 2 & 3 & 4 & 5 & 6 & 7 & 8 & \\
\hline $\begin{array}{l}\text { Pulmonary infection } \\
\text { Infection associated with: }\end{array}$ & 84 & $9^{*}$ & $34^{*}$ & $30^{*}$ & 1 & 9 & $2+$ & & $3+$ & 88 \\
\hline $\begin{array}{l}\text { Bronchial disease } \neq \\
\text { Chronic asthma } \\
\text { Cystic fibrosis } \\
\text { Carcinoma (lung or bronchus) } \\
\text { Cardiac disease } \\
\text { Surgery }\end{array}$ & $\begin{array}{r}17 \\
4 \\
1 \\
2 \\
5 \\
21\end{array}$ & $\begin{array}{l}1 \\
4\end{array}$ & $\begin{array}{c}5^{*} \\
12\end{array}$ & $\begin{array}{l}3 \\
2 \\
1 \\
1 \\
1 \\
1\end{array}$ & 1 & $\begin{array}{l}1 \\
2\end{array}$ & $1+$ & 1 & $1 \dagger$ & $\begin{array}{r}20 \\
4 \\
1 \\
2 \\
6 \\
23\end{array}$ \\
\hline
\end{tabular}

- The same biotype strain isolated from one patient on two separate occasions; tstrains of biotype 6 and biotype 8 were isolated from The same biotype strain isolated from one patient on two separate occasions, tstrains of bamples from one patient; $\ddagger$ this group of diseases included bronchitis, bronchiectasis and chronic obstructive airways disease; t tstrains of biotype 1 and biotype 2 were isolated from consecutive samples from one patient; 9 the same biotype strain isolated from one patient on three successive occasions. 
Table 3 Outer membrane profile similarity index for biotype 2 strains

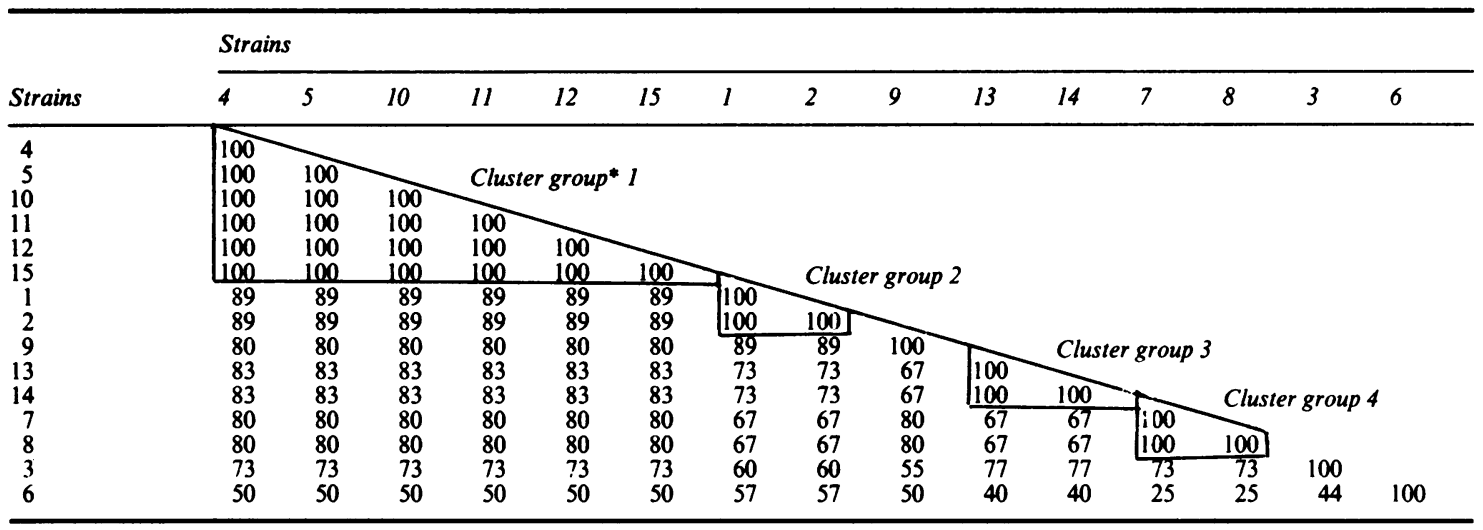

* Cluster of strains with identical OMP profiles.

patients, biotype 2 was the most common isolate (59; $41 \%)$, followed by biotypes $3(39 ; 27 \cdot 1 \%), 1(19$; $13.2 \%)$, and $5(15 ; 10 \cdot 4 \%)$. Examination of the clinical diagnosis (table 2) showed that most strains of biotypes $2(34 ; 57.6 \%), 3(30 ; 76.9 \%)$, and 5 (nine; $60.0 \%$ ) were isolated from patients with symptoms of pulmonary infection without underlying disease. A significant number of biotype 1 strains (nine; $47 \cdot 4 \%$ ) were also isolated from this group of patients.

The OMP profile was determined for 59 nonserotypable strains of $\boldsymbol{H}$ influenzae. Fifteen strains each of biotypes 1,2 , and 5 , and 14 strains of biotype 3 were examined by SDS-PAGE. Each strain contained 10 to 20 OMPs. The OMP profiles of 15 strains of biotype 2 are shown in the figure. The major proteins of biotype 2 strains had $M_{r}$ values between $1.6 \times 10^{4}$ and $5 \times 10^{4}$. Similar OMP profiles were obtained for strains of biotype 1,3 , and 5 (results not shown). Several minor bands of similar electrophoretic mobility were present in most of the strains studied.

The OMP profiles of strains within the same biotype were compared using the Dice equation. ${ }^{16}$ The similarity matrix for biotype 2 strains is shown in table 3. A large cluster, defined by a similarity coefficient of greater than $90 \%$, contained six strains. Three smaller cluster groups each containing two strains were observed. Biotype 5 strains showed three cluster groups, each containing three strains. Three cluster groups (of three, two, and two strains, respectively) were seen in biotype 1. One cluster group of two strains was observed in biotype 3 . The diversity index ${ }^{17}$ calculated for each biotype showed that the order of decreasing diversity was $3>1>5>2$.

\section{Discussion}

Non-serotypable strains of $H$ influenzae have been established as important aetiological agents in cases of sinusitis, respiratory infection in the presence of chronic bronchitis and obstructive lung disease, and bronchopneumonia in elderly men. ${ }^{18}$ Our results confirm the assertions of other workers ${ }^{718}$ that most strains of $\boldsymbol{H}$ influenzae in the respiratory secretions of both adults $(81.8 \%)$ and children $(72.5 \%)$ with serious chest infections were non-serotypable. Most strains $(82.6 \%)$ were isolated from patients over the age of 40 years. In this group of patients biotypes 2 and 3 predominated (table 1). Similar findings were made by Oberhofer and Back. ${ }^{4}$

The OMP profiles of isolates of both nonserotypable and serotypable strains of $H$ influenzae have been the subject of previous studies. ${ }^{11} 19$ Analysis of the OMP profiles of $H$ influenzae (serotype b) has shown only a limited number of subtypes. ${ }^{19}$ Nonserotypable strains have been reported ${ }^{8}$ to include a greater variety of subtypes, the OMP profiles of which are independent of growth phase and remain stable after several subcultures. ${ }^{81112}$

Generally, the OMP profiles of the non-serotypable strains were similar to those reported in earlier studies (figure) ${ }^{81112}$ Six major proteins were resolved with $\mathrm{M}_{\mathrm{r}}$ values between $1.6 \times 10^{4}$ and $5 \times 10^{4}$ (figure). In most strains pairs of major protein bands were seen with $M_{r}$ values in both the $1.6 \times 10^{4}$ to $3.0 \times 10^{4}$ and the $3.2 \times 10^{4}$ to $4.2 \times 10^{4}$ regions. The OMP profile patterns could not be assigned to a previously published subtyping scheme which was based on only two OMP bands for each subtype."

Dice analysis of strains within each of the common biotypes (1, 2, 3 and 5) was carried out. ${ }^{16} \mathrm{~A}$ value of $90 \%$ was taken as the limiting value for each cluster group. ${ }^{20}$ Separate cluster groups were identified in biotypes 1 (three groups), 2 (four groups, table 3), 3 (one group) and 5 ( 3 groups). All the other strains within a biotype had individual OMP profile patterns ( $<90 \%$ similarity). A comparison of OMP profile . 

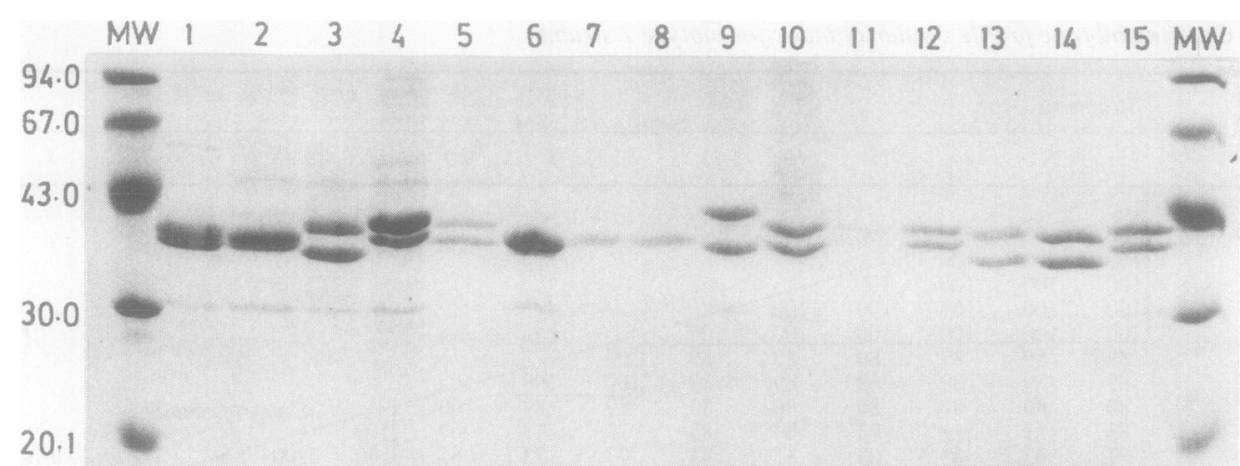

14.4

Figure OMP profiles of biotype 2 strains obtained by SDS-PAGE. The gel was stained with Coomassie brilliant blue $G$. The low molecular weight standards (lanes $M W$ ) are marked in thousands on the left. Lanes 1-15 were strains isolated from patients with symptoms of pulmonary infection.

diversity within each biotype showed that biotype 3 was the most diverse group and biotype 2 was the least diverse. With the exception of cluster group 1 of biotype 2, a clear association was not observed between a particular biotype and an individual OMP profile. Another study has also failed to detect an association between biotype and OMP subtype. ${ }^{21}$ The large number $(40 \%)$ of biotype 2 strains with the same OMP profile (table 3 ) suggests that there may be less genetic diversity within this biotype than has been found among other strains of $H$ influenzae. ${ }^{21}$ A direct comparison of the OMP profiles of strains from different biotypes was not possible due to the problems associated with inter-gel variability.

No clear correlation was observed between either the clinical state or age of the patient and the OMP profile cluster groups belonging to biotypes $1,2,3$ or 5 . Interestingly, five of the strains belonging to cluster group 1 of biotype 2 were isolated from patients with pulmonary infection that was associated with other underlying conditions.

Subsequent isolates from individual patients over a period of seven days showed identical OMP profiles (results not shown). Similar results have been reported by other workers. ${ }^{20}$ Our results confirm that the determination of OMP profiles by SDS-PAGE is a useful technique for the epidemiological study of this group of organisms. ${ }^{1222}$

The present study has shown a tentative association between a number of biotype 2 strains of $H$ influenzae and their OMP profile. These strains were isolated from adult patients with symptoms of pulmonary infection, but a clear association between biotype, OMP cluster group, and disease cannot be confirmed. Other factors such as the immunological properties of the individual strain may also be important. ${ }^{23}$ Further studies are required to determine the possible association of pulmonary disease with non-serotypable biotype 2 strains of $H$ influenzae.

We thank our colleagues at the Hull Royal Infirmary and the Humberside College of Higher Education whose cooperation made this study possible.

\section{References}

1 Murphy TF, Apicella MA. Nontypable Haemophilus influenzae:'a review of clinical aspects, surface antigens, and the human immune response to infection. Rev Infect Dis 1987;9:1-15.

2 Kilian M. A taxonomic study of the genus Haemophilus, with proposal of a new species. J Gen Microbiol 1976;93:9-62.

3 Albritton WL, Penner S, Slaney L, Brunton J. Biochemical characteristics of Haemophilus influenzae in relationship to source of isolation and antibiotic resistance. J Clin Microbiol 1978;7:519-23.

4 Oberhofer TR, Back AE. Biotypes of Haemophilus encountered in clinical laboratories. J Clin Microbiol 1979;10:168-74.

5 Wallace RJ Jr, Musher DM, Septimus EJ, et al. Haemophilus influenzae infections in adults: characterization of strains by serotypes, biotypes and $\beta$-lactamase production. $J$ Infect Dis 1981;144:101-6.

6 Granato PA, Jurek EA, Weiner LB. Biotypes of Haemophilus influenzae: relationship to clinical source of isolation, serotype and antibiotic susceptibility. Am J Clin Pathol 1983;79:73-7.

7 Long SS, Teter MJ, Gilligan PH. Biotype of Haemophilus 
influenzae: correlation with virulence and ampicillin resistance. $J$ Infect Dis 1983;147:800-6.

8 Barenkamp SJ, Munson RS, Jr, Granoff DM. Outer membrane protein and biotype analysis of pathogenic nontypable Haemophilus influenzae. Infect Immun 1982;36:535-40.

9 Gratten M. Haemophilus influenzae biotype VII. J Clin Microbiol 1983;18:1015-6.

10 Sottnek FO, Albritton WL. Haemophilus influenzae biotype VIII. J Clin Microbiol 1984;20:815-6.

11 Murphy TF, Dudas KC, Mylotte JM, Apicella MA. A subtyping system for nontypable Haemophilus influenzae based on outermembrane proteins. J Infect Dis 1983;147:838-46.

12 Loeb MR, Smith DH. Outer membrane protein composition in disease isolates of Haemophilus influenzae: pathogenic and epidemiological implications. Infect Immun 1980;30:709-17.

13 Carlone GM, Thomas ML, Rumschlag HS, Sottnek FO. Rapid microprocedure for isolating detergent-insoluble outer membrane proteins from Haemophilus species. J Clin Microbiol 1986;24:330-2.

14 Hames BD, Rickwood D. In: Gel electrophoresis of proteins: a practical approach. Oxford: IRL Press, 1987:37.

15 Laemmli UK. Cleavage of structural proteins during the assembly of the head of bacteriophage T4. Nature 1970;227:680-5.

16 Dice LR. Measures of the amount of ecological association between species. Ecology 1945;26:297-302.

17 Shannon CE, Weaver W. In: The mathematical theory of communication. Urbana: University of Illinois Press, 1962 105-6.

18 Brabender W, Hodges GR, Barnes WG. Clinical significance of serotype, biotype, and $\beta$-lactamase production of respiratory isolates of Haemophilus influenzae. Am J Clin Pathol 1984;81:85-8.

19 Barenkamp SJ, Munson RS Jr, Granoff DM. Subtyping isolates of Haemophilus influenzae type $b$ by outer-membrane protein profiles. J Infect Dis 1981;143:668-76.

20 Paterson AJ, MacSween KF, Pennington TH. Haemophilus influenzae subtyping by SDS-PAGE of whole-cell polypeptides. Epidemiol Infect 1987;99:179-89.

21 Musser JM, Barenkamp SJ, Granoff DM, Selander RK. Genetic relationships of serologically nontypable and serotype b strains of Haemophilus influenzae. Infect Immun 1986;52:183-91.

22 Barenkamp SJ, Granoff DM, Munson RS Jr. Outer-membrane protein subtypes of Haemophilus influenzae type $b$ and spread of disease in day-care centers. $J$ Infect Dis 1981;144:210-7.

23 Spinola SM, Peacock J, Denny FW, Smith DL, Cannon JG. Epidemiology of colonization by nontypable Haemophilus influenzae in children: a longitudinal study. $J$ Infect Dis 1986;154:100-9.

Requests for reprints to: Dr C H Coverdale, Microbiology Laboratory, York District Hospital, Wigginton Road, York YO3 7HE, England. 